\title{
Case Report: Acute Submandibular Glanditis Caused by Nasogastric Tube Feeding in A Subject with Poorly Controlled Diabetes Mellitus
}

Yuichiro Iwamoto ( $\square$ iwamoto.g@med.kawasaki-m.ac.jp )

Kawasaki Medical School: Kawasaki lka Daigaku https://orcid.org/0000-0001-8162-359X

\section{Takatoshi Anno}

Kawasaki Ika University Department of Internal Medicine: Kawasaki Ika Daigaku Sogo Naikagaku

\section{Katsumasa Koyama}

Kawasaki Medical School Department of Internal Medicine: Kawasaki Ika Daigaku Sogo Naikagaku

\section{Koichi Tomoda}

Kawasaki Medical School Department of Internal Medicine: Kawasaki Ika Daigaku Sogo Naikagaku

\section{Tomohiko Kimura}

Kawasaki Medical School: Kawasaki Ika Daigaku

\section{Hideaki Kaneto}

Kawasaki Medical School: Kawasaki Ika Daigaku

\section{Case Report}

Keywords: Acute submandibular glanditis, Nasogastric tube feeding, Parenteral nutrition, Elderly patient, Type 2 diabetes mellitus,

Posted Date: November 15th, 2021

DOI: https://doi.org/10.21203/rs.3.rs-1062748/v1

License: (c) (1) This work is licensed under a Creative Commons Attribution 4.0 International License. Read Full License 


\section{Abstract}

Background Enteral tube feeding is an effective method of providing nutrients for patients who are unable to meet their nutritional requirements and patients with parenteral nutrition are possible the increased risk of infection. The submandibular gland is one of the salivary glands and some of sialadenitis are caused by obstruction of the salivary outflow tract. Case presentation A 91-year-old woman had parenteral nutrition with nasogastric tube feeding. Her background history was repeated angina and myocardial infarction and performed percutaneous coronary intervention and coronary artery bypass grafting, type 2 diabetes (T2DM), heart failure, atrial fibrillation and sick sinus syndrome and performed, pacemaker placement. She was continued parenteral nutrition with nasogastric tube feeding for 20 days, and suddenly she had high fever and elevated infection markers under poorly glycemic control. We diagnosed her as acute submandibular glanditis. We treated her with antibiotics therapy, extubation, daily massage of the submandibular gland and strict glycemic control, and her neck swelling disappeared about 11 days after such treatment. Conclusions We reported acute submandibular glanditis induced by nasogastric tube feeding under poorly controlled diabetes mellitus. We have to pay attention to glycemic control in subjects under parenteral nutrition with tube feeding management.

\section{Background}

Enteral tube feeding is an effective method of providing nutrients for patients who are unable to meet their nutritional requirements. Oral environment in subjects with long-term tube feeding management frequently leads to various clinical problems. It is known that patients with parenteral nutrition are at increased risk of respiratory and intra-abdominal abscess infections [1].The submandibular gland is one of the salivary glands and some of sialadenitis are caused by obstruction of the salivary outflow tract, tumor, and after radiation therapy [2]. In such cases, congested andbacteria-laden saliva easily flows back into the salivary glands. There is a case report of a neonate who developed aseptic sialadenitis during tube feeding but was improved with antimicrobial therapy [3]. However, there have been few reports of sialadenitis during tube feeding in adults.

In this report, we show a subject who had acute submandibular glanditis caused by nasogastric tube feeding under poorly controlled diabetes mellitus. Her acute submandibular glanditis was improved with extubation of nasogastric tube and control of diabetes mellitus.

\section{Case Presentation}

A 91-year-old woman repeated admission and discharge due to aspiration pneumonia and myocardial infarction.After she received pacemaker placement for sick sinus syndrome and aspiration pneumonia, she had parenteral nutrition with nasogastric tube feeding. She was taking $400 \mathrm{kcal}$ of glucerna therapeutic nutrition shake at twice a day (breakfast and dinner) and $200 \mathrm{kcal}$ of dysphagia diet at once a day (lunch).Her background history included repeated angina and myocardial infarction (at the age of 83, 84,89 and 91 ) and performed percutaneous coronary intervention and coronary artery bypass grafting, 
type 2 diabetes (T2DM) (at 83), heart failure, atrial fibrillation and sick sinus syndrome and performed, pacemaker placement (at 91). Her glycemic control was poor (her fasting plasma glucose levels were from 200 to $400 \mathrm{mg} / \mathrm{dL}$ ) with insulin therapy (18 units/day of insulin aspart and 6units/day of insulin degludec) after started with parenteral nutrition. His medications included $30 \mathrm{mg} /$ day of azosemide, $500 \mathrm{mg} /$ day of acetazolamide, $25 \mathrm{mg} /$ day of spironolactone, $1.25 \mathrm{mg} /$ day of bisoprolol, $2.5 \mathrm{mg} /$ day of enalapril, $30 \mathrm{mg} /$ day of edoxabanand $40 \mathrm{mg} /$ day of isosorbide for hypertension, heart failureand after coronary artery bypass grafting. We continued parenteral nutrition with nasogastric tube feeding for 20 days in our hospital, and suddenly she had high fever and elevated infection markers. At that time, her height and body weight were $150.0 \mathrm{~cm}$ and $40.3 \mathrm{~kg} / \mathrm{m}^{2}$, respectively. Her vital signs were: temperature, $38.2^{\circ} \mathrm{C}$; blood pressure, $122 / 50 \mathrm{mmHg}$; heart rate, $72 \mathrm{bpm}$; oxygen saturation, $96 \%$. On clinical examination, she had neck swelling, which was bilateral, symmetric, elastic and hard with a feeling of heat. Table 1 shows laboratory data at that time. Her glycemic control was poor. Diabetes-associated data were as follows: plasma glucose, $335 \mathrm{mg} / \mathrm{dL}$; hemoglobin A1c (HbA1c), 8.6\%.Liver function and renal function were almost within normal range as follows:aspartate aminotransferase (AST), $30 \mathrm{U} / \mathrm{L}$; alanine transaminase (ALT), $51 \mathrm{U} / \mathrm{L}$; alkaline phosphatase (ALP)385 U/L; $\gamma_{\text {-glutamyltranspeptidase }\left(\gamma^{-}\right.}$ GTP), $21 \mathrm{U} / \mathrm{L}$; lactate dehydrogenase (LDH), $198 \mathrm{U} / \mathrm{L}$; creatinine (CRE), $0.50 \mathrm{mg} / \mathrm{dL}$; blood urea nitrogen (BUN), $24 \mathrm{mg} / \mathrm{dL}$.Surprisingly, inflammation markers were markedly elevated compared with 3 days before: white blood cell (WBC), from 18,980 to $31,430 / \mu \mathrm{L}$ (neutrophil, from 80.0 to $91.0 \%$ ); C-reactive protein, from 1.61 to $20.11 \mathrm{mg} / \mathrm{dL}$; procalcitonin, from 0.05 to $1.44 \mathrm{ng} / \mathrm{mL}$. We performed cervical, chestand abdominal CT for finding infection focuses, and it revealed swelling of the bilateral submandibular glands and fluffing of surrounding tissue (Figure 1,left panel). We did not detect another infectious focus including newly aspiration pneumonia. We discussed the possibility of acute submandibular glanditis caused by nasogastric tube feeding withotorhinolaryngologists, and finally we diagnosed her as acute submandibular glanditis.

We started antibiotics therapy for acute submandibular glanditis( $3 \mathrm{~g} /$ day of sulbactam/ampicillin). In addition, we performedextubation and daily massage of the submandibular gland to improve saliva secretion (20 minutes of massage with physician and several times of massage with nurse around the submandibular gland area every day) and oral environment with oral care with nurse.Moreover, we performed strict glycemic control (her fasting plasma glucose levels were from 120 to $180 \mathrm{mg} / \mathrm{dL}$ ) with insulin therapy (36 units/day of insulin aspart and 6units/day of insulin degludec), although she was elderly patient.High fever was improved about 3 daysafter starting antibiotics therapy and submandibular gland massage, and her neck swelling disappeared about 11 days after such treatment. In addition,her infectious markersweredrastically decreased (WBC, from 31,430 to10,280/ $\mu \mathrm{L}$; CRP, from 20.11 to 1.50 $\mathrm{mg} / \mathrm{dL}$; procalcitoninfrom 1.44 to $0.02 \mathrm{ng} / \mathrm{mL}$ ). Cervical CT showed that such enlargement of submandibular glandwas improved (Figure 1,right panel). Finally, she was transferred to another hospital for rehabilitation 38 days after admission.

\section{Discussion And Conclusions}


Herein, we report a subject with acute submandibular glanditis caused by nasogastric tube feeding under poorly controlled diabetes mellitus. Acute submandibular glanditiscould becaused by the reflux of bacteria-laden saliva into the submandibular gland ducts. Therefore, the bacterial reflux into the salivary glands causes the rapid onset of pain and swelling in the salivary gland area, and palpation reveals induration, edema, and tenderness. Staphylococcus aureus is the most common causative organism of bacterial sialadenitis in both adults and children [4]. The risk factors of sialadenitis are dehydration, oral filth, dental caries, oral trauma, xerostomia, low nutrition, and diabetes mellitus [5]. Our patient repeated aspiration pneumonia and received pacemaker placement for sick sinus syndrome. After then, she started receivingparenteral nutrition with nasogastric tube feeding. As a result of repeated aspiration pneumonia and started receiving parenteral nutrition with nasogastric tube feeding, her frequency of swallowing movements decreased significantly at that time. Moreover, she had poorly controlled T2DM. It has been reported that diabetics have decreased saliva secretion from their salivary glands [6]. In general, water component in saliva secretion is regulated by the parasympathetic nervous system. On the other hand, protein component in saliva secretion, which was including amylase, is regulated by the sympathetic nervous system. It is known that inpatients under hyperglycemia condition [7] or patients complicated with diabetic neuropathy [8], saliva secretion is reduced, leading to dry mouth, increased tooth decay, and salivary gland inflammation. We think that in this case,the combination of these various factors caused her acute submandibular glanditis.Since it is well known that the presence of diabetes facilitates the progression of inflammation in various tissues, we assume that among above-mentioned several possible factors, the presence of diabetes was closely associated with the development of acute submandibular glanditis caused by nasogastric tube feeding in this subject.

There are some reports aboutacute submandibular glanditisassociated with anesthesia and intubation, so-called anesthesia mumps $[9,10]$. However, there is no reports of acute submandibular glanditis caused by nasogastric tube feeding in adults, although Lindgren $\mathrm{C}$, et al. reported submandibular glanditisinneonates. In this patient, acute submandibular glanditis was improved quickly after a short course of antimicrobial therapy, although culture test was negative. Finally, the patient in that report was diagnosed as aseptic sialadenitis. These findings were similar to our present case, although the age of onset was different. We assume that in the patient,swallowing frequency was decreased due to tube feeding and consequently salivary secretion was decreased, which finally led to the development of acute submandibular glanditis. Interestingly, we think it is very important toperform strict glycemic control inelderly patientswith long-term tube feeding management for infectious disease control. T2DM subjects are immunocompromised host, especially under hyperglycemic conditions $[11,12]$.

For treatment of acute submandibular glanditis, it is important to perform not only antibiotics therapy butalso salivary gland massage, hydration, salivary stimulants and glycemic control [13]. In general, penicillin-based antibiotics are used, but we must be careful about penicillin-resistant bacteria. Moreover, if an abscess isformed in salivary glands, sometimes it is necessary to perform surgical drainage.

Taken together, we should bear in mind that parenteral nutritionwith long-term tube feeding management is one of risk factors of acute submandibular glanditis. In addition, it islikely that the risk is closely 
associated with glycemic control of T2DM, especially under poorly controlled conditions. Therefore, we have to pay attention to glycemic control in subjects under parenteral nutritionwith tube feeding management.

\section{Abbreviations}

T2DM, type 2 diabetes; HbA1c, hemoglobin A1c;AST, aspartate aminotransferase; ALT, alanine transaminase; ALP, alkaline phosphatase; $\gamma$-GTP, $\gamma$-glutamyltranspeptidase; LDH, lactate dehydrogenase; CRE, creatinine; BUN, blood urea nitrogen;WBC, white blood cell

\section{Declarations}

\section{Ethics approval and consent to participate:}

Not applicable

\section{Consent for publication:}

Written informed consent for the publication of this case report was obtained from the patient.

\section{Availability of data and material:}

Not applicable

\section{Competing interests:}

We do not have any potential conflicts of interest relevant to this article.

\section{Funding:}

The authors declare that there is no funding associated with this manuscript.

\section{Authors' contributions:}

Y.I. and T.A. researched data and wrote the manuscript. K.K., K.T.and T.K. researched data and contributed to the discussion. H.K. reviewed the manuscript.

All authors have read and approved the manuscript.

\section{Acknowledgements:}

Not applicable

\section{References}


1. Kudsk KA, Croce MA, Fabian TC, Minard G, Tolley EA, Poret HA, Kuhl MR, Brown RO.Enteral versus parenteral feeding. Effects on septic morbidity after blunt and penetrating abdominal trauma. Ann Surg. 1992;215:503-511.

2. Abdel Razek AAK, Mukherji S.Imaging of sialadenitis. Neuroradiol J. 2017;30:205-215.

3. Lindgren C, Balihodzic-Lucovic V.Aseptic sialadenitis in preterm infants associated with long-term oro-gastric tube feeding. Eur J Pediatr. 1998;157:1014-1016.

4. Nusem-Horowitz S, Wolf M, Coret A, Kronenberg J.Acute suppurative parotitis and parotid abscess in children. Int J Pediatr Otorhinolaryngol. 1995;32:123-127.

5. Viselner G, van der Byl G, Maira A, Merico V, Draghi F.Parotid abscess: mini-pictorial essay. J Ultrasound. 2013;16:11-15.

6. Watanabe M, Kawaguchi M, Ishikawa Y.[Salivary glands and diabetic stress]. Nihon Yakurigaku Zasshi. 2006;127:273-277.

7. Chavez EM, Taylor GW, Borrell LN, Ship JA.Salivary function and glycemic control in older persons with diabetes. Oral Surg Oral Med Oral Pathol Oral Radiol Endod. 2000;89:305-311.

8. Moore PA, Guggenheimer J, Etzel KR, Weyant RJ, Orchard T.Type 1 diabetes mellitus, xerostomia, and salivary flow rates. Oral Surg Oral Med Oral Pathol Oral Radiol Endod. 2001;92:281-291.

9. Reilly DJ.Benign transient swelling of the parotid glands following general anesthesia: "anesthesia mumps". Anesth Analg. 1970;49:560-563.

10. Akçaboy EY, Akçaboy ZN, Alkan H, Gogus N."Anesthesia mumps" after electroconvulsive therapy anesthesia. J ECT. 2011;27:e21-22.

11. Shah BR, Hux JE.Quantifying the risk of infectious diseases for people with diabetes. Diabetes Care. 2003;26:510-513.

12. Benfield T, Jensen JS, Nordestgaard BG.Influence of diabetes and hyperglycaemia on infectious disease hospitalisation and outcome. Diabetologia. 2007;50:549-554.

13. Wilson KF, Meier JD, Ward PD.Salivary gland disorders. Am Fam Physician. 2014;89:882-888.

\section{Tables}

Table 1 Laboratory dataobserved at fever up during nasogastric tube feeding. 


\begin{tabular}{|c|c|c|c|c|c|}
\hline Variable & Result & $\begin{array}{l}\text { Reference } \\
\text { range }\end{array}$ & Variable & Result & $\begin{array}{l}\text { Reference } \\
\text { range }\end{array}$ \\
\hline Blood biochemistry & & & Peripheral blood & & \\
\hline Total protein (g/dL) & 6.3 & $6.6-8.1$ & White blood cells $(/ \mu \mathrm{L})$ & 31430 & $3300-8600$ \\
\hline Albumin (g/dL) & 2.1 & $4.1-5.1$ & Neutrophil (\%) & 91.0 & $28.0-78.0$ \\
\hline Globulin (g/dL) & 4.2 & $2.2-3.4$ & $\begin{array}{l}\text { Red blood cells }\left(\times 10^{4} /\right. \\
\mu \mathrm{L})\end{array}$ & 304 & $386-492$ \\
\hline $\begin{array}{l}\text { Total bilirubin } \\
(\mathrm{mg} / \mathrm{dL})\end{array}$ & 0.4 & $0.4-1.5$ & Hemoglobin (g/dL) & 10.1 & $11.6-14.8$ \\
\hline AST (U/L) & 30 & $13-30$ & Hematocrit (\%) & 28.8 & $35.1-44.4$ \\
\hline ALT (U/L) & 51 & $7-23$ & Platelets $\left(\times 10^{4} / \mu \mathrm{L}\right)$ & 27.3 & $15.8-34.8$ \\
\hline LDH (U/L) & 198 & $124-222$ & Infectious marker & & \\
\hline ALP (U/L) & 385 & $106-322$ & $\mathrm{CRP}(\mathrm{mg} / \mathrm{dL})$ & 20.11 & $<0.14$ \\
\hline Y-GTP (U/L) & 21 & $9-32$ & Procalcitonin (ng/mL) & 1.44 & $0.00-0.05$ \\
\hline BUN (mg/dL) & 24 & $8-20$ & Diabetes marker & & \\
\hline Creatinine (mg/dL) & 0.50 & $0.46-0.79$ & $\begin{array}{l}\text { Plasma glucose } \\
(\mathrm{mg} / \mathrm{dL})\end{array}$ & 335 & \\
\hline Cholinesterase (U/L) & 121 & $201-421$ & Hemoglobin A1c (\%) & 8.6 & $4.9-6.0$ \\
\hline Uric acid (mg/dL) & 6.3 & $2.6-5.5$ & Urinary test & & \\
\hline Sodium (mmol/L) & 133 & $138-145$ & Urinary $\mathrm{pH}$ & 5.5 & $5.0-7.5$ \\
\hline $\begin{array}{l}\text { Potassium } \\
(\mathrm{mmol} / \mathrm{L})\end{array}$ & 2.6 & $3.6-4.8$ & Urinary protein & $1+$ & - \\
\hline \multirow[t]{5}{*}{ Chloride (mmol/L) } & 104 & $101-108$ & Urinary sugar & $3+$ & - \\
\hline & & & Urinary ketone body & - & - \\
\hline & & & Urinarybilirubin & - & - \\
\hline & & & Urinaryblood & - & - \\
\hline & & & Urinary $\mathrm{pH}$ & 5.5 & $5.0-7.5$ \\
\hline
\end{tabular}

Abbreviation: AST, aspartate aminotransferase; ALT, alanine aminotransferase; $L D H$, lactate dehydrogenase; ALP, alkaline phosphatase; $ү$-GTP, $ү$-glutamyltranspeptidase; BUN, blood urea nitrogen; CRP, C-reactive protein 


\section{Figures}

\section{Just after high fever}

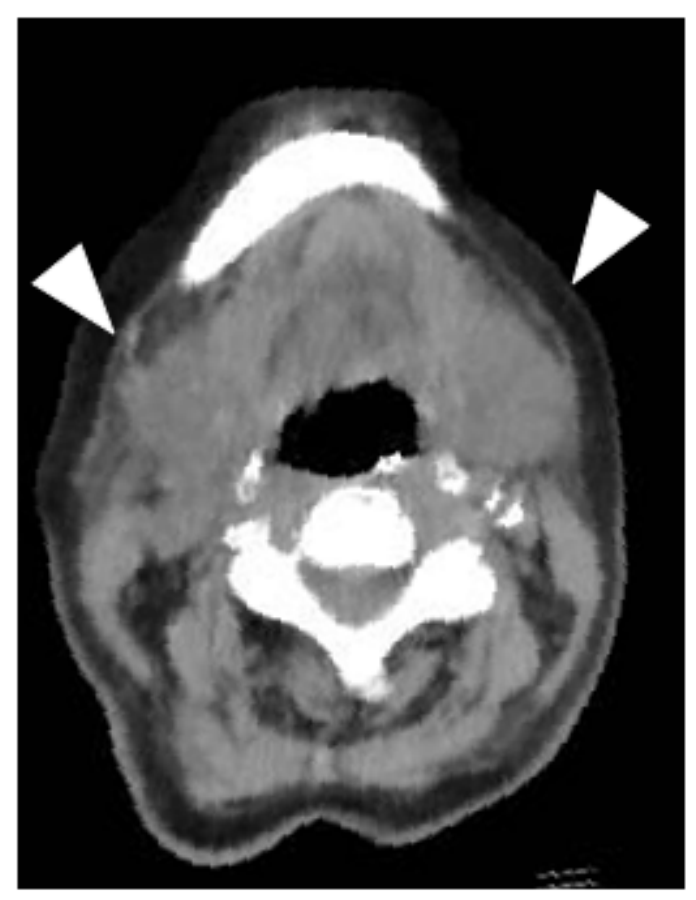

About one month after high fever

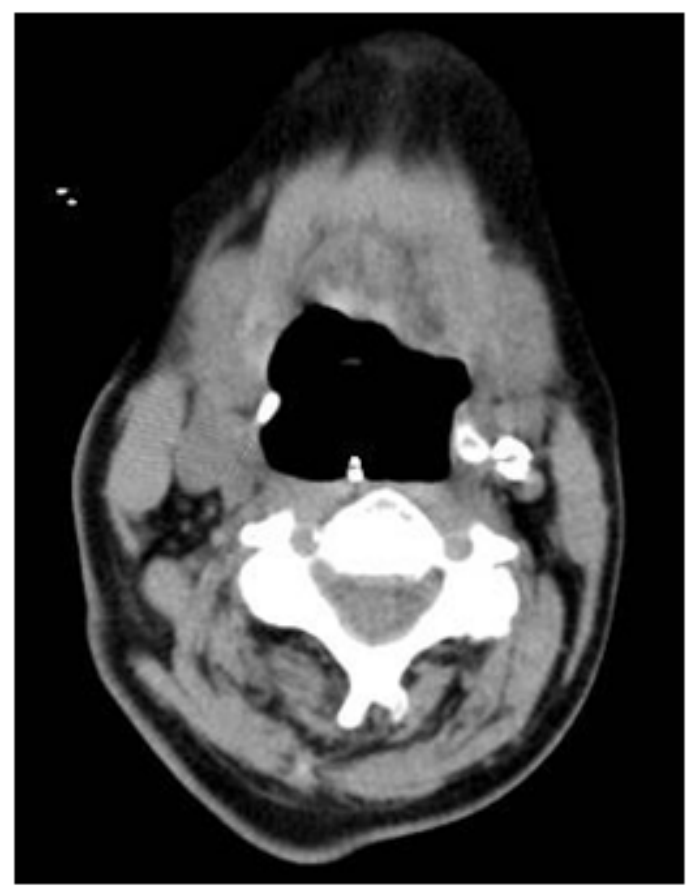

\section{Figure 1}

Cervical computed tomography (CT) after high fever in this subject receivingparenteral nutrition with nasogastric tube feeding for 20 days in our hospital. Cervical CTrevealedswelling of the bilateral submandibular glands and fluffing of surrounding tissue (white arrowhead) (left panel). Cervical CT about one month after high fever showed that enlargement of submandibular gland was drastically improved (right panel). 